\title{
Potential antidiabetic and antioxidant activities of Morus indica and Asystasia gangetica in alloxan- induced diabetes mellitus
}

This article was published in the following Dove Press journal:

Journal of Experimental Pharmacology

9 Febuary 2010

Number of times this article has been viewed

\author{
R Pradeep Kumar' \\ D Sujatha ${ }^{2}$ \\ TS Mohamed Saleem' \\ C Madhusudhana Chetty' \\ D Ranganayakulu² \\ 'Department of Pharmacology, \\ Annamacharya College of Pharmacy, \\ Rajampet, India; ${ }^{2}$ Department of \\ Pharmacology, Sri Padmavathi School \\ of Pharmacy, Tirupathi, India
}

\begin{abstract}
Herbal drugs are frequently considered to be less toxic and also free from side effects, than synthetic ones. Hence, the present study was designed to investigate one such combination of herbal drugs, Asystasia gangetica and Morus indica for their antidiabetic and antioxidant potential against alloxan-induced diabetes in albino rats. The effect of both individual and a combination of Asystasia gangetica and Morus indica on blood glucose and liver glycogen were studied in the diabetic rats. The study also assessed for the effect of selected plant extracts for their effect on Superoxide dismutase (SOD), catalase (CAT), reduced glutathione (GSH) and Lipid peroxidation (LPO) in the homogenates of the pancreas. The results of the present study attests significant antidiabetic and antioxidant potential for the selected plants individually and also in combination as a prominent decrease in blood glucose and liver glycogen was observed in the rats treated with the extracts of the selected plants. Similarly, the levels of the protective antioxidant enzymes like SOD, CAT and GSH were increased along with decrease in the LPO levels. The present study provides a scientific evidence for antidiabetic and antioxidant potential of Asystasia gangetica and Morus indica. Further studies to isolate bioactive compounds will pave the way to identify potential lead compounds for developing safe and efficacious antidiabetic agents.
\end{abstract}

Keywords: hypoglycemic effect, herbal drugs, lipid peroxidation, hyperglycemia, diabetic animals

\section{Introduction}

Diabetes is a worldwide major health problem with approximately $5 \%$ of the world's population suffering from the disease. Worldwide projections suggest that more than 300 million people will contract diabetes by the year 2025 and the global cost of treating this disease and its complications could reach US\$1 trillion annually. ${ }^{1}$ The effective control of blood glucose is the key in preventing or reversing diabetic complications and improving the quality of life for both type I and type II diabetic patients. Although different types of oral hypoglycemic agents are available along with insulin for the treatment of diabetes mellitus, none offers complete glycemic control. ${ }^{2}$

Traditional plant medicines are used throughout the world for a range of diabetic presentations. Therefore, an investigation of such agents from traditional medicinal plants has become particularly important. India has a rich history of using various potent herbs and herbal components for treating diabetes. Many Indian plants have previously been investigated for their beneficial use in different types of diabetes. ${ }^{3}$ To date, there are many hundreds of herbs and traditional herbal formulas reported to have been used for the treatment of diabetes mellitus. ${ }^{4}$
Correspondence: R Pradeep Kumar Department of Pharmacology, Annamacharya College of Pharmacy, Rajampet, AP, India-516126

$\mathrm{Tel}+9 \mid 8565249309$

Fax +91 8565250229

Email pradeepkumar.repana@gmail.com 
Morus indica (Mulberry tree) of the family Moraceae has been widely cultivated in countries all over the world from temperate to tropical areas. Different parts of the plant are used as herbal medicine for blood serum glucose reduction, cholesterol and lipid level reduction, antiphlogistic, diuretic and expectorant effects. Andallu and Varadacharyulu have reported antidiabetic activity of Morus indica in streptozotocin induced diabetes in rats. ${ }^{5}$ Asystasia gangetica of the Acanthaceae family has been claimed to have antiasthmatic, anthelmentic and antidiabetic property. ${ }^{6}$ The leaves are also widely used as a food source, because it contains a high concentration of protein, amino acids, minerals and fiber. ${ }^{7}$ Synergistic combinations of more than one hypoglycemic have been used by many physicians for proper glycemic control. ${ }^{8}$ Therefore it will be of value to pharmacologically screen any such combinations. Hence, the present study is an attempt to study Morus indica and Asystasia gangetica individually and also in combination against alloxan-induced diabetes.

\section{Materials and methods Drugs and chemicals}

Alloxan monohydrate was purchased from Sigma-Aldrich, St. Louis, MO, USA. Glibenclamide was a gift from Cipla Ltd, Mumbai, India. All biochemical estimations were assayed by using kits from Span Diagnostics Ltd., Surat, India. All other biochemicals used in this experiment were purchased from Sigma-Aldrich, St. Louis, MO, USA. All chemicals were analytical grade.

\section{Experimental animals}

Male Wistar rats of body weight 180-200 g were obtained from the central Animal House, Sri Padmavathi School of Pharmacy Tirupathi, India. The animals were fed on standard pellet diet (Hindustan Lever, Mumbai, India) and water ad libitum. The rats used in the this study were maintained in accordance with guidelines of the Committee for the Purpose of Supervision and Control of Experiments on Animals (CPCSEA), India and the study was approved by the ethical committee (1016/a/06/CPCSEA/006/2009).

\section{Preparation of plant extract}

Leaves of Morus indica and Asystasia gangetica were collected from the Rayachoty, Kadapa and Mudhumalai hills, Coimbatore in the period from October to November 2008. Their botanical identities were authenticated by Dr Yashodamma, Department of Botany, Sri Ventateswara University, Tirupati, India. The shade dried leaves were powdered to obtain a course granule. Approximately $250 \mathrm{~g}$ of this dried powder of both Morus indica and Asystasia gangetica were extracted with $90 \%$ and $70 \%$ ethanol respectively by continuous hot percolation, using soxhlet apparatus, (before that the crude powders were extracted with various solvents in increasing polarity and the antioxidant potential principle like flavonoids were identified in ethanolic extract). The resultant dark brown extract was then concentrated up to $100 \mathrm{~mL}$ on Rota evaporator under reduced pressure. The concentrated crude extracts were then lyophilized before being used for the study.

\section{Phytochemical screening}

The alcoholic extracts obtained were subjected to preliminary phytochemical screening, to identify the chemical constituents. The methods of analysis employed were those described by Harbone and Trease. ${ }^{9,10}$

\section{Experimental induction of diabetes in rats} The rats were injected intraperitoneally with alloxan monohydrate dissolved in sterile normal saline at a dose of $150 \mathrm{mg} / \mathrm{kg}$ body weight. ${ }^{11}$ After 2 weeks, rats with moderate diabetes, having glycosuria (indicated by Benedict's qualitative test) and hyperglycemia (with a blood glucose of $200-300 \mathrm{mg} / \mathrm{dL}$ ) were used for the experiment.

\section{Oral glucose tolerance test (OGTT)}

Rats were fasted overnight and divided into five groups with 6 animals in each group. Group-I received distilled water, to serve as control. Group-II animals were treated with glibenclamide $(0.5 \mathrm{mg} / \mathrm{kg}$, per os $)$ to serve as a standard. Group-III animals were treated with Asystasia gangetica leaf extract, group-IV animals were treated with Morus indica leaf extract and group- $\mathrm{V}$ animals treated with both Asystasia gangetica and Morus indica leaf extracts. The control, standard and test groups were treated with drugs 30 minutes prior to a glucose load $(2.5 \mathrm{~g} / \mathrm{kg}$, per os $)$. Blood samples were collected at 15 , 30, 45, 60, 75, 90 and 120 minutes after glucose loading. Serum was then separated and glucose levels measured immediately. ${ }^{12}$

\section{Experimental design}

The six groups of six rats each were grouped as follows: Group1; Normal treated rats. Group2; Diabetic control rats. Group 3; Diabetic rats given aqueous solution of glibenclamide ( $500 \mu \mathrm{g} / \mathrm{kg}$, per os) for 28 days. Group 4; Diabetic rats given extract of Asystasia gangetica $(100 \mathrm{mg} / \mathrm{kg}$, per os $)$ for 28 days. Group 5; Diabetic rats given extract of Morus 
indica (400 mg/kg, per os) for 28 days. Group 6; Diabetic rats given extract of Morus indica (400 mg/kg, per os) in combine with the extract of Asystasia gangetica $(100 \mathrm{mg} / \mathrm{kg}$, per os) for 28 days. Blood samples were drawn on days 7 , 14, 21 and 28 from the retro orbital venous plexus of rats under ether anesthesia using a glass capillary tube after they had been fasted of 12 hours. The blood was then centrifuged at 2,500 rpm for 10 minutes to obtain serum. Serum was used for the biochemical estimation of blood glucose. After 28 days the rats were sacrificed and the pancreas and liver were harvested, these were then immediately frozen in liquid nitrogen for biochemical analysis.

\section{Biochemical parameters}

Blood glucose was estimated from the serum by using standard kits. Glycogen content in the liver was estimated by the method described by Potter and Elvehjem. ${ }^{13}$ Lipid peroxidation (LPO) in the pancreas was estimated by the method described by Slater and Sawyer. ${ }^{14}$ Pancreatic superoxide dismutase (SOD) was estimated by the method described by Misra and Fridovich. ${ }^{15}$ Reduced glutathione (GSH) in the pancreas was estimated by the method described by Moran and colleagues. ${ }^{16}$ Pancreatic catalase (CAT) was estimated by the method described by Aebi. ${ }^{17}$

\section{Statistical analysis}

Data for various biochemical parameters were analyzed using analysis of variance (ANOVA) and the group means were compared by Tukey-Kramer test (GraphPad Version 3.06, La Jolla, CA, USA). Values were considered statistically significant when at $P<0.05$.

\section{Results}

\section{Phytochemical screening}

Results of phytochemical screening of both the extracts revealed the presence of flavonoids, terpenes, phytosterols.

\section{Effect of Asystasia gangetica and Morus indica on serum glucose in normal fasted rats}

In the control groups a significant increase in blood glucose levels was noticed after 60 minutes which was followed by a reduction after 120 minutes (Table 1). Treatment with the standard drug glibenclamide (group-III), blood glucose rose at 30 minutes followed by subsequent fall up to 120 minutes. It was observed from the present study that the administration of Asystasia gangetica and Morus indica leaf extracts increased the glucose levels after 30 minutes with the hypoglycemia rebound effect observed after 120 minutes. Rats treated with combinations of both Asystasia gangetica and Morus indica leaf extracts showed an increase in blood glucose levels at 30 minutes followed by a decrease in blood glucose levels from 60 minutes onwards. A significant reduction in the blood sugar level was observed in the tested groups when compared with control group.

\section{Effect of Asystasia gangetica and Morus indica on serum glucose in diabetic rats}

In animals treated with alloxan (G-II) $(150 \mathrm{mg} / \mathrm{kg}$ intraperitoneally) a significant increase in the serum glucose levels was observed on day 7, 14, 21 and 28 when compared to the normal group (G-I). Group-III treated with standard drug (glibenclamide $-0.5 \mathrm{mg} / \mathrm{kg}$ per os) showed a significant decrease in serum glucose levels on day 7, 14, 21 and 28 when compared to the diabetic control group (G-II). On administration of Asystasia gangetica and Morus indica leaf extracts alone and in combination groups (G-IV, $\mathrm{V}$ and $\mathrm{VI}$ ), the blood glucose levels were decreased on day 7, 14, 21 and 28 when compared to the control group G-II (Table 2).

Table I Effect of Asystasia gangetica and Morus indica on glucose tolerance in normal fasted rats

\begin{tabular}{|c|c|c|c|c|c|c|}
\hline \multirow[t]{3}{*}{ Group } & \multirow[t]{3}{*}{ Treatment } & \multicolumn{5}{|c|}{ Serum glucose $(\mathrm{mg} / \mathrm{dL})($ Mean \pm SEM) } \\
\hline & & \multicolumn{5}{|c|}{ Time after glucose administration in minutes } \\
\hline & & 0 & 30 & 60 & 90 & 120 \\
\hline I & Control & $67.53 \pm 4.20$ & $107.81 \pm 4.40$ & $137.12 \pm 4.12$ & $151.7 \pm 4.26$ & $115.27 \pm 5.20$ \\
\hline II & Standard & $61.54 \pm 6.87$ & $71.35 \pm 6.02^{\mathrm{a}}$ & $68.12 \pm 5.99^{\mathrm{a}}$ & $73.12 \pm 6.30^{\mathrm{a}}$ & $64.12 \pm 5.96^{\mathrm{a}}$ \\
\hline III & AGLE & $70.24 \pm 4.29$ & $82.12 \pm 4.20^{\mathrm{a}}$ & $94.12 \pm 5.60^{\mathrm{a}}$ & $97.12 \pm 4.1 I^{\mathrm{a}}$ & $67.43 \pm 5.20^{\mathrm{a}}$ \\
\hline IV & MILE & $57.34 \pm 4.91$ & $94.20 \pm 5.25^{\mathrm{a}}$ & $110.12 \pm 5.20^{\mathrm{a}}$ & $94.20 \pm 5.0 \mathrm{I}^{\mathrm{a}}$ & $78.6 \pm 4.08^{\mathrm{a}}$ \\
\hline v & AGLE + MILE & $55.06 \pm 5.67$ & $90.74 \pm 4.93^{\mathrm{a}}$ & $80.12 \pm 5.12^{\mathrm{a}}$ & $71.13 \pm 5.14^{\mathrm{a}}$ & $60.14 \pm 4.02^{\mathrm{a}}$ \\
\hline
\end{tabular}

Notes: ${ }^{a} P<0.00 I$, when compared to control (G-I).

Abbreviations: AGLE, Asystasia gangetica leaf extract; MILE, Morus indica leaf extract. 
Table 2 Effect of Asystasia gangetica and Morus indica on serum glucose levels in diabetic rats

\begin{tabular}{|c|c|c|c|c|c|c|}
\hline \multirow[t]{2}{*}{ Group } & \multirow[t]{2}{*}{ Treatment } & \multicolumn{5}{|c|}{ Serum glucose $(\mathrm{mg} / \mathrm{dL})($ Mean \pm SEM $)$} \\
\hline & & Day 0 & Day 7 & Day I4 & Day 21 & Day 28 \\
\hline I & Normal & $72.40 \pm 6.45$ & $86.70 \pm 6.45$ & $76.80 \pm 5.45$ & $68.57 \pm 5.97$ & $81.70 \pm 5.45$ \\
\hline II & Control & $218.70 \pm 16.56$ & $184.00 \pm 16.46^{\mathrm{a}}$ & $197.80 \pm 16.26^{a}$ & $219.60 \pm 16.85^{a}$ & $222.30 \pm 18.44^{a}$ \\
\hline III & Standard & $186.6 \pm 16.45$ & $93.75 \pm 6.65^{b}$ & $92.18 \pm 10.74^{b}$ & $98.00 \pm 7.26^{b}$ & $92.56 \pm 9.47^{b}$ \\
\hline IV & AGLE & $206.20 \pm 18.44$ & $99.68 \pm 8.78^{b}$ & $89.06 \pm 6.88^{b}$ & $93.07 \pm 8.95^{b}$ & $95.00 \pm 6.25^{b}$ \\
\hline V & MILE & $214.00 \pm 19.50$ & $71.87 \pm 5.49^{b}$ & $73.43 \pm 8.35^{b}$ & $81.22 \pm 10.49^{b}$ & $84.23 \pm 6.38^{\mathrm{b}}$ \\
\hline VI & AGLE + MILE & $228.80 \pm 19.25$ & $81.62 \pm 7.55^{\mathrm{b}}$ & $67.34 \pm 6.45^{b}$ & $68.12 \pm 6.46^{b}$ & $61.34 \pm 5.45^{\mathrm{b}}$ \\
\hline
\end{tabular}

Notes: ${ }^{a} P<0.00 \mathrm{I}$, when compared to control (G-I). ${ }^{\text {b } P}<0.00 \mathrm{I}$, when compared to control (G-II).

Abbreviations: AGLE, Asystasia gangetica leaf extract; MILE, Morus indica leaf extract.

\section{Effect of Asystasia gangetica and Morus indica on liver glycogen levels}

The alloxan control group (G-II) had a significant decrease in levels of liver glycogen, when compared to the normal group (G-I) on the 28th day. There was a significant increase in the hepatic glycogen of the standard group treated with glibenclamide (G-III), when compared to the alloxan control group (G-II). On treatment with ethanolic leaf extracts of Asystasia gangetica and Morus indica alone and in combination (G-IV, G-V and G-VI) a significant increase in hepatic glycogen was also observed on 28th day, when compared to the alloxan control group (G-II) (Table 3).

\section{Effect of Asystasia gangetica and Morus indica on antioxidant parameters}

In alloxan induced diabetic rats (G-II), the antioxidant enzymes SOD, CAT, GSH decreased significantly and LPO increased significantly, when compared to the normal group (G-I). The standard group (G-III) showed a significant

Table 3 Effect of Asystasia gangetica and Morus indica on liver glycogen levels in diabetic rats

\begin{tabular}{lll}
\hline Group & Treatment & $\begin{array}{l}\text { Liver glycogen }(\mathbf{m g} / \mathbf{g}) \\
\text { (Mean } \pm \text { SEM) on day 28 }\end{array}$ \\
\hline I & Normal & $5.90 \pm 0.71$ \\
II & Control & $3.40 \pm 0.92^{\mathrm{a}}$ \\
III & Standard & $6.64 \pm 1.0^{\mathrm{b}}$ \\
IV & AGLE & $6.40 \pm 1.12^{\mathrm{b}}$ \\
V & MILE & $7.20 \pm 0.78^{\mathrm{c}}$ \\
VI & AGLE + MILE & $7.09 \pm 0.67^{\mathrm{d}}$ \\
\hline
\end{tabular}

Notes: ${ }^{a} p<0.05$, when compared to normal (G-I). ${ }^{\mathrm{p} P}<0.05$, when compared to control (G-II). ${ }^{c} P<0.01$, when compared to control (G-II). ${ }^{d} P<0.001$, when compared to control (G-II).

Abbreviations: AGLE, Asystasia gangetica leaf extract; MILE, Morus indica leaf extract. increase in SOD, CAT, GSH levels and a decrease in LPO levels, when compared with control group (G-II). On treatment with the plant extracts of Asystasia gangetica and Morus indica alone and in combination (G-IV, G-V and G-VI) a significant increase in SOD, CAT, GSH levels (Figures 1-3) and a significant decrease in the LPO levels was observed when compared with the alloxan control (G-II) (Figure 4) group respectively.

\section{Discussion}

Experimentally induced diabetes in animals has the advantage allowing the analysis of the biochemical, hormonal and morphological parameters that take place not only during the induction of a diabetic state but also after it has taken place and during its evolution to a severe insulin deficiency or even death. This strategy has great advantages but it has to be considered that none of the animal models with induced diabetes corresponds exactly to the human type-2 diabetes mellitus. Nonetheless they provide adequate models to investigate the pathogenic mechanism that leads to hyperglycemia and its consequences..$^{18}$ Alloxan became the first diabetogenic chemical agent when Dunn and Letchie accidentally produced islet-cell necrosis in rabbits while researching the nephrotoxicity of uric acid derivatives. Alloxan is a specific toxin that destroys the pancreatic $\beta$ cells, provoking a state of primary deficiency of insulin without affecting other islet types. ${ }^{19,20}$ Hence, alloxan was selected to induce diabetes in the present study.

Currently available drugs for the treatment of Diabetes mellitus have a number of limitations, such as adverse effects and a high rate of secondary failure. ${ }^{21}$ As there is a growing trend towards using natural remedies adjunct to conventional therapy, traditionally used plants might provide a useful source of new hypoglycemic compounds. ${ }^{22}$ Although Asystasia gangetica may be described as a medicinal plant 


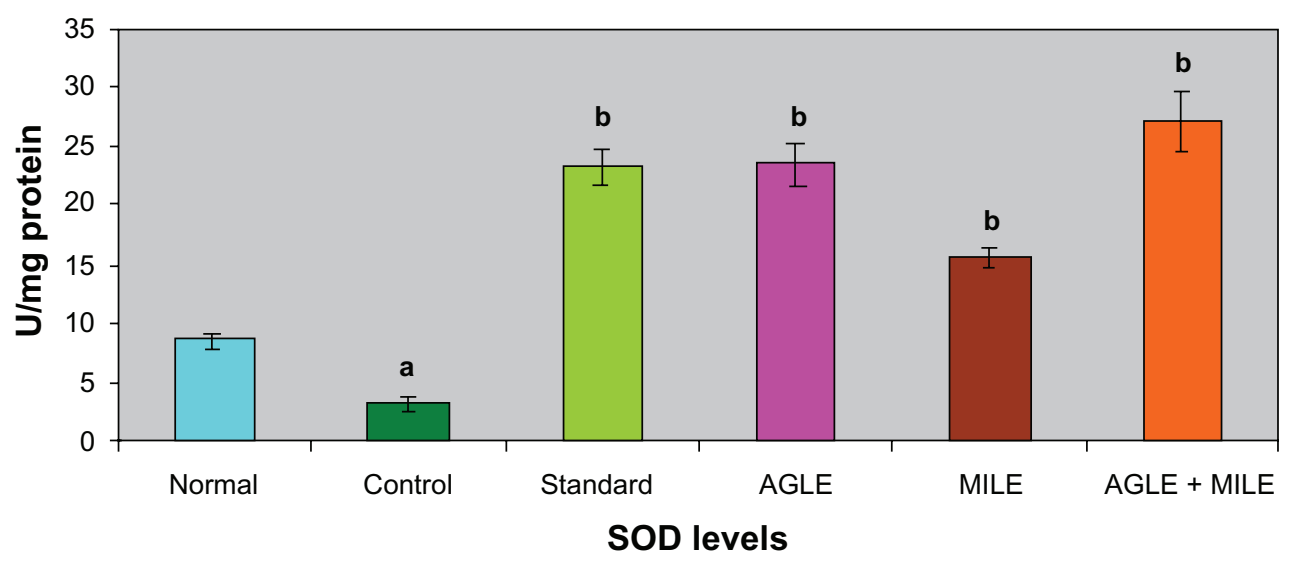

Figure I Effect of Asystasia gangetica and Morus indica on SOD levels in pancreas.

All values shown are mean \pm SEM and $n=6$. ${ }^{a} P<0.001$, when compared to normal animals. ${ }^{b} p<0.001$, when compared to control animals.

Abbreviation: SOD, Pancreatic superoxide dismutase.

used for various purposes, no scientific reports exist on its antihyperglycemic and antioxidant properties. The present study demonstrates for the first time the antihyperglycemic and antioxidant properties of Asystasia gangetica. The extracts of Morus indica have been reported to possess medicinal properties, including hypoglycemic, hypotensive and diuretic activities. ${ }^{5}$ The hypoglycemic and antioxidant effect of mulberry leaves or shoot culture extract has been demonstrated using streptozotocin induced diabetic animals. ${ }^{5,23}$ Although the importance of the hypoglycemic activity of mulberry leaves has been recognized, its effect in combination with other herbs, such as Costus igneus, have also been investigated. ${ }^{24}$ The present study shows the effect of mulberry leaves in combination with Asystasia gangetica against alloxan induced diabetes.
Recent studies have shown that modifications of systemic glycemia in OGTT reflect the activity of the intestinal glucose transporter SGLT $1 .{ }^{25}$ We therefore further examined the effect of oral Asystasia gangetica and Morus indica in normal rats subjected to an OGTT. Asystasia gangetica and Morus indica reduced the overall OGTT response, both individually and in combination as efficiently as the reference oral hypoglycemic drug glibenclamide. These results therefore confirm the reduction of intestinal glucose transport in vivo and may be due to increased insulin sensitivity as observed in previous studies. ${ }^{26}$ Taken altogether, these considerations lead us to believe that inhibition of intestinal glucose absorption by the selected plants in this study and their combinations may be the mechanism in the observed hypoglycemic effect.

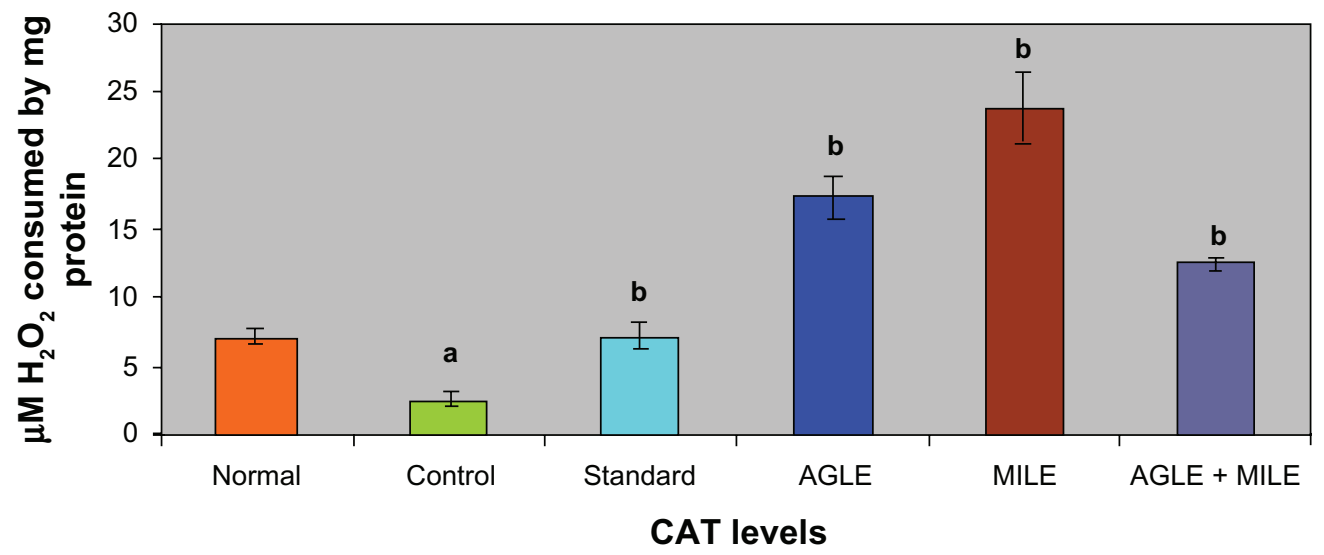

Figure 2 Effect of Asystasia gangetica and Morus indica on CAT levels in pancreas.

All values shown are mean \pm SEM and $n=6$. ${ }^{a} P<0.00 \mathrm{I}$, when compared to normal animals. ${ }^{b} P<0.00 \mathrm{I}$, when compared to control animals. Abbreviation: CAT, Pancreatic catalase. 


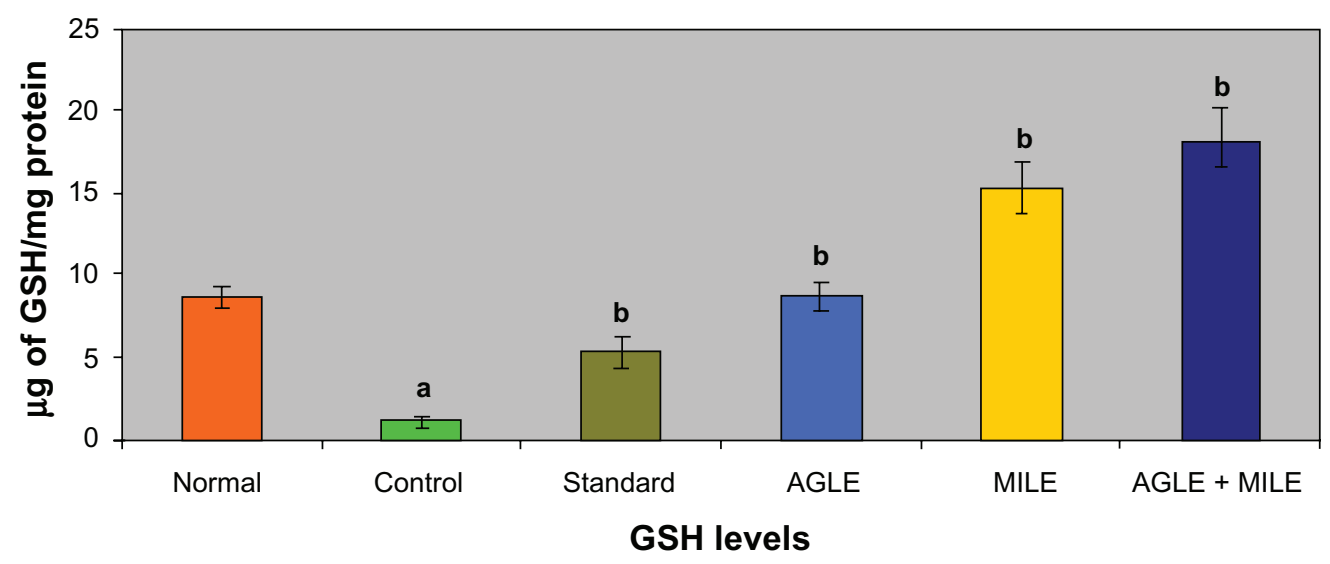

Figure 3 Effect of Asystasia gangetica and Morus indica on GSH levels in pancreas.

All values shown are mean \pm SEM and $n=6$. ${ }^{a} P<0.00$ I, when compared to normal animals. ${ }^{b} P<0.001$, when compared to control animals.

Abbreviation: GSH, Glutathione.

A number of plants have been reported to possess hypoglycemic effects and the possible mechanism suggested for such hypoglycemic actions could be through the increased insulin secretion from $\beta$-cells of islets of Langerhans or its release from bound insulin. Alternatively such hypoglycemic effects of plant extracts could also be because of their insulin-like actions. ${ }^{27,28}$ Similar mechanisms may be considered responsible for the hypoglycemic action shown by Asystasia gangetica and Morus indica alone and in combination in diabetic rats.

The alloxan treated animals exhibited a decrease in hepatic glycogen content which may be due to an increase in glucose-6-phosphatase activity and a low level of hexokinase activity. ${ }^{29}$ The observed hypoglycemic action of Asystasia gangetica and Morus indica may be responsible for the observed increase in hepatic glycogen. An increase in hepatic glycogen content in Asystasia gangetica and Morus indica administered animals suggests that the activation of glycogen synthase for which the substrate glucose-6phosphate could have been readily provided by increased hexokinase activity. ${ }^{30,31}$ These observations clearly indicate the potential of Asystasia gangetica and Morus indica to reduce gluconeogenesis both alone and in combination. Thus, Asystasia gangetica and Morus indica, in diabetic rats, reduced blood glucose levels and increased glycogenesis and glycolysis, reduced gluconeogenesis and brought the glucose metabolism towards normal levels. Moreover, the effect of combination of Asystasia gangetica and Morus indica on the carbohydrate metabolism in diabetic rats is found to be similar to that of glibenclamide.

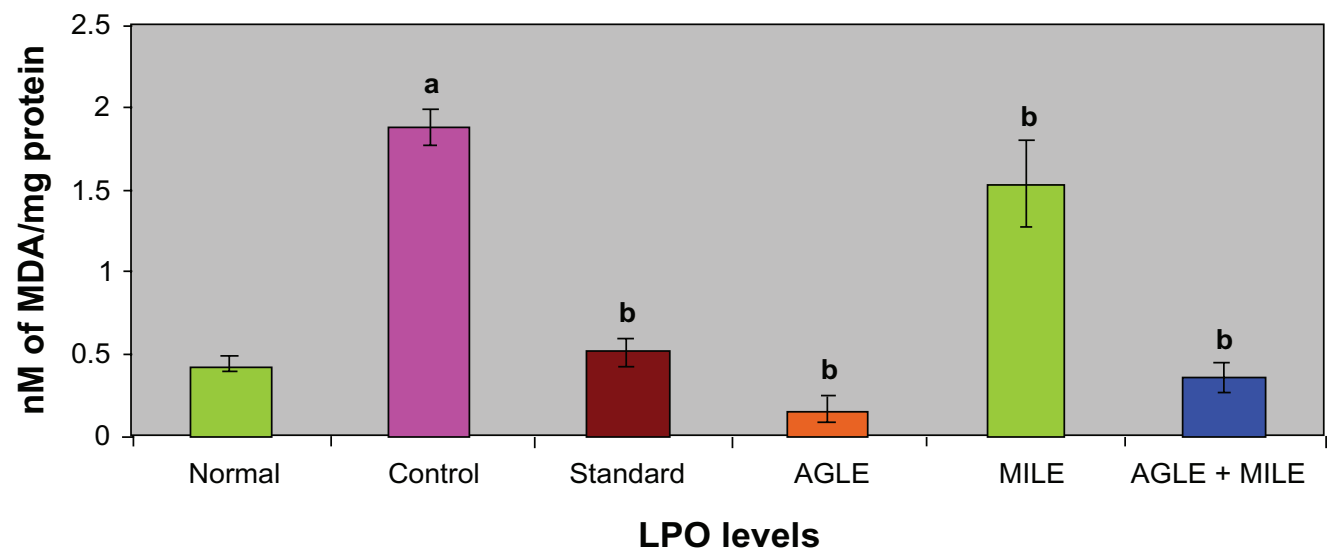

Figure 4 Effect of Asystasia gangetica and Morus indica on LPO levels in pancreas.

All values shown are mean \pm SEM and $n=6$. ${ }^{a} P<0.00$ I, when compared to normal animals. ${ }^{b} P<0.001$, when compared to control animals. Abbreviation: LPO, Lipid peroxidation. 
Lipid peroxidation is one of the characteristic features of chronic diabetes and lipid peroxidation mediated tissue damage has been observed in diabetic conditions. ${ }^{32}$ Hyperglycemia generates reactive oxygen species (ROS), which in turn cause lipid peroxidation and membrane damage. ${ }^{33}$ Increased concentrations of lipid peroxides in the liver are reported to decrease cytochrome P450 and cytochrome b5 activities, which may affect the drugs metabolizing activity in chronic diabetes. ${ }^{34}$ Glutathione (GSH), a tripeptide normally present in high concentrations intracellularly constitutes the major reducing capacity of the cytoplasm ${ }^{35}$ and protects the cellular system against the toxic effects of lipid peroxidation. ${ }^{36}$ The diabetic animals in the present study registered lowered levels of GSH reflecting its increased utilization owing to oxidative stress while, a significant elevation of GSH levels in Asystasia gangetica and Morus indica in alone and combination administered to diabetic rats coincided with a significant decline in lipid peroxidation. It appears that the effect of Asystasia gangetica and Morus indica on GSH could be at two levels, - either through increasing the biosynthesis of GSH or by inhibiting its utilization by reducing oxidative stress.

The antioxidant enzymes SOD and CAT play an important role in reducing cellular stress. SOD scavenges the superoxide radical by converting it to hydrogen peroxide and molecular oxygen, ${ }^{37}$ while CAT brings about the reduction of hydrogen peroxides and protects higher tissues from the highly reactive hydroxyl radicals. ${ }^{38}$ In the present investigation both these enzymes registered low levels of activity in diabetic controls indicating diabetes-induced stress. Such a decline in these enzyme activities has also been reported earlier. ${ }^{39,40}$ The Asystasia gangetica and Morus indica, both alone and in combination, when administered to the diabetic animals improved both SOD and CAT activities substantially, reflecting the antioxidant potency of Morus indica and Asystasia gangetica. The effects of Asystasia gangetica and Morus indica alone and in combination on antioxidants (GSH, SOD, CAT and LPO) were found to be better than those of glibenclamide administered diabetic animals.

In conclusion, the present study reveals that the Asystasia gangetica and Morus indica (alone and in combination) are antihyperglycemic and a potent antioxidant agent. The bioactive component(s) responsible for the observed activities are not precisely known but it may be one or more of the phytochemical constituents established to be present in the leaf extracts. Our phytochemical screening reported that the presence of flavonoids in both the extracts, compounds which might be the constituents responsible for these activities. Further identification and isolation of these constituents may be fruitful.

\section{Disclosures}

The authors report no conflicts of interest in this work.

\section{References}

1. Rahul S, Sanjay K, Abhay KS. Antidiabetic potential of Butea monosperma in rats. Fitoterapia. 2006;77:86-90.

2. Jiang D, Zhen-Dan H, Ren-Wang J, Wen-Cai Y, Hong-Xi X, Paul PB. Antiviral flavonoids from the root bark of Morus alba. L Phytochemistry. 2003;62:1235-1238.

3. Pulok KM, Kuntal M, Kakali M, Peter JH. Leads from Indian medicinal plants with hypoglycemic potentials. J Ethanopharmacol. 2006;106:1-28.

4. Jia W, Gao W, Tang L. Antidiabetic herbal drugs officially approved in China. Phytother Res. 2003;17:1127-1134.

5. Andallu B, Varadacharyulu NC. Antioxidant role of mulberry (Morus indica. L) leaves in streptozotocin-diabetic rats. Clinica Chemica Acta. 2003;338:3-10.

6. Akaha PA, Ezike AC, Nwafor SV, Okoli CO, Enwerem NM. Evaluation of the anti-asthmatic property of Asystasia gangetica leaf extracts. J Ethnopharmacol. 2003;89:25-36.

7. Yeoh HH, Wong PFM. Food value of lesser utilized tropical plants. Food Chemistry. 1993;46:239-241.

8. Sheen AJ. Drug interaction of clinical imparact with antihyperglycemic agent colon on update. Drug Safe. 2005;28:601-631.

9. Harbone JB, Baxter HH. Phytochemical Dictionary: A hand Book of Bioactive Compound from plants. Washington, D.C: Taylor and Francis; 1993. p. 237.

10. Trease GE, Evans MC. Text book of Pharmacognosy. 13th ed. London: Bailiere Tindall; 1989.

11. Katsumata K, Katsumata Y, Ozawa T, Katsumata K. Potentiating effects of combined usage of three sulfonylurea drugs on the occurrence of alloxan diabetic rats. Horm Metab Res. 1999;25:125-126.

12. Babu V, Gangadevi Y, Subramoniam A. Anti-hyperglycemic activity of ethanol Cassia kleinii leaf extract in glucose fed normal rats and alloxaninduced diabetic rats. Indian J Pharmacol. 2002;34:409-415.

13. Potter VR, Elvehjem CA. A modified method for the study of tissue oxidations. J Biol Chem. 1936;114:495-504.

14. Slater TF, Sawyer BC. The stimulatory effects of carbon tetrachloride and other halogenoalkanes on peroxidative reactions in rat liver fractions in vitro. General features of the systems used. Biochem J. 1971;123:805-814.

15. Misra HP, Fridovich I. The role of superoxide anion in the autoxidation of epinephrine and a simple assay for superoxide dismutase. $J$ Biol Chem. 1972;247:3170-3175.

16. Moran MS. Levels of glutathione, glutathione reductase and glutathioneStransferase activities in rat lung and liver. Biochimica et Biophysica Acta. 1979;582:67-78.

17. Aebi H. Catalase In: Methods of enzymatic analysis. HU Bergmeyer, editor. Weinheim Verlag Chemic Academic Press; 1974. p. 673-685.

18. Bailey C, Flatt. Animal syndromes of non insulin dependent diabetes. In: Pick J, William G, editors. Text book of diabetes. London: Backwell Science; 1997. p. 23.1-23.5.

19. Dunn JS, Sheehan HL, Mclechie NG. Necrosis of langerhans produced experimentally. Lancet. 1943;241(6242):484-487.

20. Goldener MG, Gomori G. Studies on the mechanism of alloxan diabetes. Endocrinology. 1964;35:241-248.

21. Koski RR. Oral Antidiabetic agents: A comparative review. J Pharm Pract. 2004;17(1):39-48.

22. Bailey CJ, Day C. Traditional plant medicines as treatments for diabetes. Diabetes Care. 1989;12:553-564.

23. Kelkar SM, Bapat VA, Ganapathi TR, Kaklij GS, Rao PS, Heble MR Determination of hypoglycemic activity in Morus indica L. (Mulberry) shoot cultures. Curr Sci. 1996;71:71-72. 
24. Urooj A, Devi VD. Hypoglycemic potential of Morus indica. L and Costus igneus. Nak. - A preliminary study. Indian J Exp Bio. 2008;46: 614-616.

25. Ducroc R, Voisin T, El Firar A, Laburthe M. Orexins control intestinal glucose transport by distinct neuronal, endocrine, and direct epithelial pathways. Diabetes. 2007;56:2494-2500.

26. Le PM, Benhaddou-Andaloussi A, Elimadi A, Settaf A, Cherrah Y, Haddad P. The petroleum ether extract of Nigella sativa exerts lipidlowering and insulin-sensitizing actions in the rat. J Ethnopharmacol. 2004;94:251-259.

27. Twaij HA, Al-Badr AA. Hypoglycemic activity of Artemisia herba alba. J Ethnopharmacol. 1988;24:123-126.

28. Kasiviswanath R, Ramesh A, Kumar KE. Hypoglycemic and antihyperglycemic effect of Gmelina asiatica Linn. in normal and in alloxan induced diabetic rats. Biol Pharm Bull. 2005;28:729-732.

29. Shirwaikar A, Rajendran K, Kumar CD, Bodla R. Antidiabetic activities of aqueous leaf extract of Annona squamosa in streptozotocin-nicotinamide type 2 diabetic rats. J Ethnopharmacol. 2004;91:171-175.

30. Lawrence JC, Roach PJ. New insights into the role and mechanism of glycogen synthase activation by insulin. Diabetes. 1997;46:541-547.

31. Bouche C, Serdy S, Kahn CR, Goldfine AB. The cellular fate of glucose and its relevance in type 2 diabetes. Endocr Rev. 2004;25:807-830.
32. Feillet-Coudray C, Rock E, Coudray C. Lipid peroxidation and antioxidant status in experimental diabetes. Clin Chim Acta. 1999;284:31-43.

33. Hunt J, Dean RT, Wolff SP. Hydroxyl radical production and autoxidative glycosylation. Glucose autoxidation as the cause of protein damage in the experimental glycation model of diabetes and ageing. Biochem J. 1988;256:205-212.

34. Levin W, Lu AY, Jacobson M, Kuntzman R, Poyer JL, McCay PB. Lipid peroxidation and the degradation of cytochrome P-450 heme. Arch Biochem Biophys. 1973;158:842-852.

35. Lu SC. Regulation of hepatic glutathione synthesis: current concepts and controversies. FASEB J. 1999;13:1169-1183.

36. Nicotera P, Orrenius S. Role of thiols in protection against biological reactive intermediates. Adv Exp Med Biol. 1986;197:41-51.

37. Robinson BH. The role of manganese super oxide dismutase in health and disease. J Inherit Met Dis. 1998;21:598-603.

38. Brioukhanov AL, Netrusov AI. Catalase and superoxide dismutase: distribution, properties, and physiological role in cells of strict anaerobes. Biochemistry. 2004;69:949-962.

39. Selvam R, Anuradha CV. Effect of oral methionine on blood lipid peroxidation. Nutr Biochem. 1990;1:653-665.

40. Stanely MPP, Menon VP. Antioxidant action of Tinospora cordifolia root extract in alloxan diabetic rats. Phytother Res. 2001;15:213-218.
Journal of Experimental Pharmacology

\section{Publish your work in this journal}

The Journal of Experimental Pharmacology is an international, peerreviewed, open access journal publishing original research, reports, reviews and commentaries on all areas of laboratory and experimental pharmacology. The manuscript management system is completely online and includes a very quick and fair peer-review system.

\section{Dovepress}

Visit http://www.dovepress.com/testimonials.php to read real quotes from published authors. 